Reprod. Nutr. Dévelop., 1987, 27 (1 B), 213-214.

\title{
Différence entre races bovines dans le déracinement de l'herbe pâturée
}

\author{
P. LE NEINDRE ('), R. KILGOUR ( $\left.{ }^{*}\right)$
}

Laboratoire de l'Elevage bovin,

I.N.R.A. Theix, 63122 Ceyrat, France.

(*) Ruakura Animal Research Station, P.B., Hamilton, New Zealand.

Summary. Grass-pulling during grazing is sometimes an important agronomic problem because the life-span of the pasture is shortened. The results of this study demonstrate breed differences in grass-pulling. Friesian cows pulled the grass more than sahiwal-cross dairy cows.

Ce texte rapporte des observations effectuées en Nouvelle Zélande au cours de l'automne (mars-avril) 1986 au Centre de Recherches de Ruakura. Le pâturage intensif des animaux est accompagné d'un piétinement mais également d'un déracinement de l'herbe, tout spécialement du ray-grass anglais, qui entraîne la mort de la plante (Charles, 1979 ; Hughes, 1971 ; Hodgson, 1973 ; Boswell, 1977 ; Feyter, 1985). Feyter (1985) met en évidence certains facteurs favorisant cette dégradation. Une période de sécheresse est un de ces facteurs. Enfin Boswell (1977) observe que les bovins déracinent plus l'herbe que les ovins. Nos résultats portent sur la comparaison du comportement au pâturage de vaches Frisonnes et croisées Sahiwal $\times$ Frisonnes ou Jersiaises.

Matériel et méthodes. Six vaches Frisonnes (poids moyen $500 \mathrm{~kg}$, âge compris entre 4 et 12 ans) et 6 vaches croisées Sahiwal (Zébu laitier) $\times$ Frisonnes ou Jersiaises (poids moyen $476 \mathrm{~kg}$, âge 4 ans), toutes taries, sont comparées.

Tous ces animaux pâturent à l'automne une même parcelle de ray-grass anglais-trèfle blanc semés. Une phase d'adaptation de plus de 40 jours avant les mesures a été observée. Une surface supplémentaire d'environ $150 \mathrm{~m}^{2}$ est attribuée chaque jour à chaque troupeau. Les mesures sont effectuées pendant deux jours consécutifs. Des mesures supplémentaires sont effectuées lors d'une journée où chaque groupe dispose d'une surface double.

Une grille comprenant 36 carrés de $20 \times 20 \mathrm{~cm}$ est posée sur le sol juste après le changement de parcelle. La mesure consiste à compter le nombre de carrés dans lesquels de l'herbe est déracinée quelle que soit l'importance de ce déracinement. Ces relevés sont répétés sur l'ensemble de la parcelle au moins 25 fois lors de chaque jour de mesure.

Résultats et discussion. En moyenne, les nombres de carrés où de l'herbe a été arrachée sont de 6,83 et 1,89 sur les 36 de chaque grille respectivement pour les Frisonnes et les croisées Sahiwal lorsqu'elles disposent de $150 \mathrm{~m}^{2}$ par groupe. Les valeurs sont légèrement inférieures respectivement 6,00 et 1,44 carrés (non significativement) lorsque cette surface est de $300 \mathrm{~m}^{2}$.

La figure 1 représente le pourcentage de grilles ayant de 0 à plus de 10 carrés contenant de l'herbe arrachée. Par exemple la fréquence des grilles avec moins de

(1) Résultats obtenus pendant son séjour au centre de Recherches de Ruakura, Nouvelle Zélande. 
4 carrés est de $26,6 \%$ pour les Frisonnes et de 92,4 \% pour les croisées Sahiwal. II apparaît très clairement que les Frisonnes arrachent beaucoup plus I'herbe que les autres animaux, cette herbe arrachée étant d'ailleurs constituée essentiellement de ray-grass anglais.

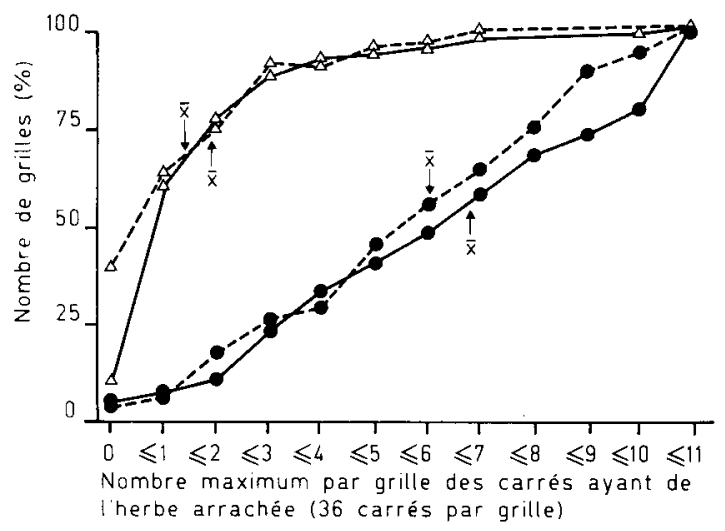

FIG. 1. - Influence de la race de vaches laitières sur le déracinement de l'herbe. $\Delta$ croisée Sahiwal $\times$ taurins laitiers ; Frisonne ; . $50 \mathrm{~m}^{2} /$ vache/jour ; carrés avec de l'herbe arrachée.

II est évident que ces résultats ont été obtenus en Nouvelle Zélande, sur des prairies à base de ray-grass anglais. II serait nécessaire de les confirmer dans d'autres conditions, sur des prairies d'autres graminées et avec d'autres types d'animaux et de mesurer son impact sur la pérennité de la prairie. Enfin, l'étude des différences comportementales ou anatomiques entre génotypes devraient permettre de comprendre ce phénomène.

Boswell C. C., 1977. Proc. N.Z. Grass/. Soc., p. 56-65.

Charles A. H., 1979. In Proc. Symp., organised by the Brit. Grassland Soc. Ed: Charles A. H., Haggar R. J., 137-140.

Feyter C., 1985. Dairy Exporter, 61, p. 38.

Hodgson J., 1973. Vaxtodling, 28, p. 74-80.

Hughes R., 1971. Rep. Welsh Plant Breed. Stat., p. 35. 